International Journal of Child, Youth and Family Studies (2011) 1 \& 2: 65-82

\title{
A PROSPECTIVE EXAMINATION OF THE RELATIONSHIP BETWEEN CHILDHOOD NEGLECT AND JUVENILE DELINQUENCY IN THE CAMBRIDGE STUDY IN DELINQUENT DEVELOPMENT
}

\author{
Lila Kazemian, Cathy Spatz Widom, and David P. Farrington
}

\begin{abstract}
The relationship between childhood neglect and later life outcomes is an understudied topic. This study employs data from the Cambridge Study in Delinquent Development, a longitudinal follow-up of 411 working-class males in London, to examine (a) the profiles of the boys who were neglected in childhood and (b) the relationship between childhood neglect and juvenile delinquency, controlling for other risk factors. Findings reveal that boys who were neglected in childhood were characterized by other adverse events in childhood. Childhood neglect predicted both self-reported and official offending in adolescence, although these effects eventually dissipated with the introduction of other measures of childhood risk. The odds ratios are particularly large for official offending, with the odds of juvenile conviction being over four times higher for individuals who were exposed to neglect in childhood when compared to those who were not. Neglect and other adverse childhood characteristics were more predictive of official offending than self-reported offending, suggesting potential stigmatization effects. Implications of these findings as well as priority areas for future research are discussed.
\end{abstract}

Key words: neglect, maltreatment, childhood risk factors, juvenile delinquency.

Address correspondence to: Lila Kazemian, 899 Tenth Avenue, Department of Sociology, Room 520.01, New York, NY, 10019. Tel: (212) 484-1301. E-mail: lkazemian@jjay.cuny.edu.

Lila Kazemian, Ph.D. is Associate Professor at the John Jay College of Criminal Justice, City University of New York.

Cathy Spatz Widom, Ph.D. is Distinguished Professor at the John Jay College of Criminal Justice, City University of New York.

David P. Farrington, Ph.D. is Professor of Psychological Criminology at Cambridge University. 
International Journal of Child, Youth and Family Studies (2011) 1 \& 2: 65-82

The negative consequences of child maltreatment have been well established (Allen, 2008; Arata, Langhinrichsen-Rohling, Bowers, \& O’Farrill-Swails, 2005; Colman \& Widom, 2004; Dutton \& Hart, 1992; Horwitz, Widom, McLaughlin, \& White, 2001; Lansford et al., 2007; Maxfield \& Widom, 1996; Rodgers et al., 2004; Smith, Ireland, \& Thornberry, 2005; Smith \& Thornberry, 1995; Stouthamer-Loeber, Loeber, Homish, \& Wei, 2001; Widom, 1989; Widom, Czaja, \& Dutton, 2008; Widom, DuMont, \& Czaja, 2007; Widom, White, Czaja, \& Marmorstein, 2007), but studies focusing specifically on childhood neglect have been scarce. Studies that have specifically examined the long-term effects of childhood neglect have generally found that this form of maltreatment predicts later adverse behavioral outcomes (Tyler, Johnson, \& Brownridge, 2008).

Neglect is frequently defined as "the failure of a parent or other person with responsibility for the child to provide needed food, clothing, shelter, medical care, or supervision such that the child's health, safety, and well-being are threatened with harm” (U.S. Department of Health and Human Services, 2010b). Official statistics indicate that neglect is the most common form of child maltreatment. According to the United States Department of Health and Human Services (2010a), of the 772,000 victims of child maltreatment in 2008, $71.1 \%$ were subject to neglect, $16.1 \%$ were physically abused, $9.1 \%$ suffered sexual abuse, and $7.3 \%$ were psychologically maltreated (please note that the same child may be exposed to more than one type of maltreatment). Various studies have observed the same trend in the distribution of types of maltreatment, namely the particularly high prevalence of neglect (Hildyard \& Wolfe, 2002; Legano, McHugh, \& Palusci, 2009; Manly, Kim, Rogosch, \& Cicchetti, 2001). Interestingly, while the prevalence of physical and sexual abuse in the United States appears to have declined over the past two decades, this has not been the case for childhood neglect (Jones, Finkelhor, \& Halter, 2006). Nonetheless, despite the high prevalence of neglect and the general consensus regarding the negative effects of neglect on development and adult outcomes (Glaser, 2002), research on this form of maltreatment remains largely scarce in the literature (Hildyard \& Wolfe, 2002; Manly et al., 2001). In addition to the fact that neglect is the most common form of child maltreatment, it is also characterized by a more chronic and less sporadic character when compared to other forms of abuse (physical or sexual; see Hildyard \& Wolfe, 2002).

The current study aims to investigate the link between childhood neglect and juvenile delinquency using a longitudinal study originally designed to study the development and risk factors for delinquency (West \& Farrington, 1973). While some research has suggested that childhood neglect exerts a significant impact on internalizing problems (Bolger \& Patterson, 2001), very little is known about the mid- to long-term effects of neglect on behavioral outcomes such as offending.

It has often been argued that prospective longitudinal studies are crucial to the understanding of the intricate relationships between childhood victimization experiences and later outcomes (Widom, Raphael, \& DuMont, 2004). Widom et al. (2004) conclude that "recall bias in the report of childhood victimization can artifactually cause an association between selfreported childhood abuse and neglect and later health outcomes" (p. 720). (For an overview of limitations on retrospective reports, see Fagan, 2001; Kazemian \& Farrington, 2005). As such, prospective longitudinal data are desirable in the study of the long-term consequences of childhood neglect. 
International Journal of Child, Youth and Family Studies (2011) 1 \& 2: 65-82

\section{The Link between Childhood Neglect and Later Offending}

Few studies have investigated the effect of child neglect on subsequent delinquency and offending (Chapple, Tyler, \& Bersani, 2005). Moreover, studies that focus solely on neglect are scarce; research on neglect generally employs cumulative constructs that combine neglect with other forms of child maltreatment.

Mersky and Reynolds' (2007) analyses rely on substantiated cases (i.e., cases reported to the Child Protection Division of the Illinois Department of Child Services or juvenile court) of physical abuse and neglect that occurred prior to age 12. The authors conducted separate analyses for physical abuse and neglect, and found that neglect was associated with violent delinquency. However, they further argue that the possible combination of abuse and neglect "may have confounded the estimates reported for physical abuse and neglect" (p. 254). Cohen, Smailes, and Brown (2004) collected information about self-reported and official child abuse and neglect in upstate New York. Their findings show that neglect is less predictive of arrests in adulthood when compared to other forms of maltreatment (i.e., physical and sexual abuse), but the authors acknowledge that these results may be due to weak statistical power.

Chapple et al. (2005, pp. 39-40) discussed some of the negative consequences associated with childhood neglect and argued that "neglected children experience limited parent-child interactions, which are often devoid of attention and caring, and subsequently are unlikely to have the ability to regulate their emotions, curb impulsivity, or choose appropriate peers”. Chapple et al. used data from the children of the National Longitudinal Survey of Youth to investigate the link between child neglect and violent behavior in adolescence and found that the exposure to neglect (particularly physical neglect) was associated with a greater likelihood of subsequent self-reported violent behavior (measured up to ages 15 to 17).

In contrast to studies utilizing self-reports, several studies have relied on official measures of offending. Generally, these findings suggest that the likelihood of arrest is higher among neglected children when compared to non-abused and non-neglected children (see English, Widom, \& Brandford, 2002; Zingraff, Leiter, Myers, \& Johnsen, 1993). Widom and Maxfield (2001, p. 1) summarized findings from their research on childhood abuse and neglect and maintained that "being abused or neglected as a child increased the likelihood of arrest as a juvenile by $59 \%$, as an adult by $28 \%$ and for a violent crime $30 \%$ ” when compared to nonabused and non-neglected children. Two additional studies reported similar findings for maltreatment, but did not report results specifically for neglect (Smith \& Thornberry, 1995; Stouthamer-Loeber et al., 2001). In short, the small body of research that has examined the longterm effects of childhood neglect has generally found that this form of childhood maltreatment is associated with subsequent offending behavior.

In light of the gaps in research on neglect, the current study employs prospective longitudinal data collected for a sample of British males to address some of these shortcomings. The design of the Cambridge Study provides many advantages in studying the consequences of childhood neglect, including the use of a community sample that defines neglected children without recourse to official child protection agency records, a prospective longitudinal follow-up 
International Journal of Child, Youth and Family Studies (2011) 1 \& 2: 65-82

that includes comparisons between neglected and non-neglected children (and varying degrees of neglect), self-reported and official measures of delinquency, and controls for other potential correlates of delinquency. We have four goals:

1. To identify individuals who experienced neglect in childhood;

2. To describe their individual, social, and family characteristics;

3. To contrast the profile of the neglected group to other groups; and

4. To examine whether childhood neglect predicts juvenile delinquency among the

Cambridge study males.

\section{Methods}

\section{Data}

Data used in this study were collected in the context of the Cambridge Study in Delinquent Development (CSDD), a prospective longitudinal survey of 411 mainly Caucasian males from a working-class area of London. The study participants were first contacted in 196162, at the age of 8-9 years old, and were interviewed on eight subsequent occasions. They completed questionnaires in school at ages 8, 10, and 14. These questionnaires assessed various cognitive (intelligence, attainment, personality, etc.) and social (school, friends, family, etc.) measures. The boys were also interviewed in a research office at ages 16, 18, and 21, and in their homes at ages 25, 32, and 48. More detailed descriptions of the sample can be found elsewhere (Farrington, 2003; Farrington et al., 2006; Farrington, Coid, \& West, 2009). The current study focuses on childhood indicators measured during the first two interviews, when the boys were between 8 and 10 years old. All measures documented at this age reflect social worker assessments based on parent and child interviews, unless otherwise indicated (e.g., teacher ratings).

The current paper addresses some of the recommendations put forth by Zuravin (1999, pp. 40-42) with regard to the measurement of childhood neglect. Namely, we employ data from different sources to obtain information on neglect (e.g., teacher, parent, and social worker reports; see also Williams \& Herrera, 2007), integrate psychological and physical components in our operationalization of neglect, and select a reliable and valid classification of neglect. Moreover, in line with Zuravin's recommendation, we provide detail regarding the criteria for classification.

\section{Offending Measures}

Measures of offending include both self-reports and official records of convictions. Official records of convictions are available between ages 10 and 50 for the following offenses: shoplifting, theft from vehicles, theft of vehicles, theft of bicycles, theft from machines, theft from work, other theft, burglary, fraud, receiving, suspicious behavior (loitering with intent), robbery, assault and wounding, insulting or threatening behavior, carrying an offensive weapon, sex offenses, drug offenses, arson, vandalism, and driving under the legally allowed age. The age of criminal responsibility in England is 10 years old, and offenders were regarded as juveniles up to the age of 16. Due to relatively low prevalence rates for convictions, a dichotomous measure of officially processed offenses is employed and logistic regression is appropriate for this analysis. 
Self-reported offenses measured in adolescence include various forms of theft (burglary, shoplifting, theft of vehicles, joyriding, theft from vehicles, theft from machines, theft from work, theft from home), assault, vandalism, and fraud (total of 19 items with alpha $=0.85$ ). The analysis of self-reported offending relies on gravity scores, which are a composite measure integrating the frequency and seriousness of offending This measure was selected because it enables us to give more weight to more serious crimes and less weight to more minor offenses. We drew on Wolfgang, Figlio, Tracy, and Singer's (1985) seriousness scale and Le Blanc and Fréchette’s (1989) average seriousness scores (homicide: 31.1; sex offenses: 14.3; personal attack: 13.21; aggravated theft: 11.54; personal larceny: 7.1; motor vehicle theft: 6.7; burglary: 6.43; fraud: 6; common theft: 5.07; shoplifting: 2.2; vandalism: 1.8; petty larceny: 1; public mischief: 0.7). These seriousness scores were multiplied by the offending frequency and added up for all offenses at ages 14 and 16, resulting in cumulative offending gravity scores (see Kazemian, Farrington, \& Le Blanc, 2009; Le Blanc \& Fréchette, 1989, for a more detailed explanation of gravity scores). Because some individuals did not complete the interview at age 16 (though attrition rates were quite low - 405 individuals completed the interview at age 14 and 397 at age 16), the maximum self-reported offending score measured at either age 14 or 16 was selected for the analyses. Gravity scores were logged, which enabled us to fulfill the assumptions of ordinary least squares regression.

\section{Conceptualizing Childhood Neglect and Other Childhood Risk Factors}

Legano et al. (2009) describe three types of neglect: physical (insufficient food, inadequate clothing, etc.), emotional (inadequate affection on the part of the caregivers), and educational neglect (excessive absenteeism from school or inadequate educational services). To the extent that such measures were available in the data, we have integrated these three components in our measure of childhood neglect.

A ten-item construct of childhood neglect was computed $(K R-20=0.72)$, integrating measures of neglectful behavior of both parents. The items were selected on the basis of scales developed in existing studies on neglect (Nikulina, Widom, \& Czaja, in press). The first two items measure neglectful maternal and paternal attitudes, which refer to the overall neglectful attitudes of parents towards the child. Housing neglect documents the lack of care of the interior of the house, with a neglected interior reflecting a dirty or untidy environment, or other evidence of gross carelessness. Physical neglect of the child refers to noticeable neglect of the child's clothing, hygiene, or food (as rated by a social worker). In addition, this component includes a negative assessment of the child's cleanliness and tidiness as rated by the teacher, who identified children regarded as noticeably below average with regard to their physical appearance. Educational neglect measures the parents' lack of knowledge of school activities, of the child's difficulties at school, and the extent to which they help the child with school work; uninterested parents had little or no knowledge of the child's progress. Emotional neglect refers to the absence of praise, rewards, or special privileges for the child's good behavior. It also measures whether the father behaves in a disinterested manner in his interactions with the child, and whether he expresses little interest towards his children more generally. The last item reflects supervisory neglect, which is assessed through the under-vigilance of parents, the poor quality of supervision, and lack of knowledge of the child's activities. 
Based on the distribution of these cumulated scores, three groups emerged: individuals who did not show any evidence of childhood neglect $(n=202,51.8 \%)$, those who were possible cases or ambiguous cases of neglect (i.e., who had 1 to 3 neglect factors; $n=138,35.4 \%$ ), and those who were victims of neglect on the basis of the indicators described above (4 or more neglect factors; $n=50,12.8 \%$ ). We used the top quartile of scores to identify the neglect group. The no-neglect and possible neglect groups will be respectively referred to as NN and PN groups.

Using information from ages 8 and 10 assessments, we also include four other childhood risk constructs that may also be markers of early outcomes associated with childhood neglect. Problem behavior $(K R-20=0.66)$ is a five-item construct that reflects ratings by parents or social workers (risk-taking/adventurousness, resistance to discipline, and problematic conduct disorder), and by peers (daring attitude and troublesomeness). Cognitive abilities $(K R-20=0.66)$ reflect low mechanical reading quotient, low verbal IQ, low non-verbal IQ, and the teacher's assessment of poor arithmetic ability. School maladjustment $(K R-20=0.73)$ is a six-item scale that documents the child's negative behaviors in school, as reported by teachers (including problem behavior, poor work or laziness, lack of interest in school, poor attendance due to unjustified absences, lack of concentration, and difficult relations with other classmates). Highrisk family environment $(K R-20=0.71)$ includes 7 dichotomous items reflecting inadequate family income, poor housing (unsatisfactory or dilapidated premises), whether the family is supported by social agencies, convictions of older siblings, inconsistency in parental discipline (confusing rules between parents or allowing the child to play off one parent against the other), slack parental rules (rarely enforced rules), and poor marital relations between parents. Given that it has been argued that parental convictions are one of the most salient predictors of offending by the Cambridge study males (Farrington, 2003), parental criminality is examined separately from other measures of family risk.

Some additional variables did not fulfill internal consistency requirements, and constructs could not be created for these measures. These variables were however included in the descriptive analyses in order to investigate differences across the three neglect groups. Measures in infancy assess whether the child was a fretful baby, experienced feeding problems or delayed walking or talking, and whether the pregnancy was unwanted by the mother. Parental background variables document the background of adversity of the parents (one or both grandparents having died or deserted before the parents were 16, and/or the parent spent substantial time in a children's home, orphanage, or foster home), background of poverty (refers to extreme poverty), background of unhappiness (social worker assessment based on the balance of information about parents' home background, and on what complaints they voiced about it), the lack of higher schooling, erratic employment records (which includes frequent and unexplained changes of employment, being a poor worker, or frequently unemployed), and a history of significant illnesses or accidents. Measures of parental traits include a social worker rating of the intelligence of the mother, severe nervousness of parents (social worker rating based on past history as well as on reactions during the whole period of contact with parents from intake), and the parents' poor health at the time of the interview. 
International Journal of Child, Youth and Family Studies (2011) 1 \& 2: 65-82

\section{Results}

Table 1 provides an overview of the characteristics of the men in the sample who display signs of neglect, possible neglect (PN), and no evidence of neglect (NN) at ages 8 to 10. Even by applying the conservative Bonferroni correction, Table 1 suggests a stronger prevalence of childhood risk factors among the neglect group, particularly across measures of parental criminality, high-risk family environment, problem behavior, school maladjustment, and cognitive abilities. These results suggest the co-occurrence of neglect and other risk factors in childhood.

Table 1. Description of Social and Individual Characteristics of Three Neglect Groups at Age 8-10, $n=390$.

$\begin{array}{llll}\begin{array}{l}\text { No Neglect } \\ (n=202)\end{array} & \begin{array}{l}\text { Possible Neglect } \\ (n=138)\end{array} & \begin{array}{l}\text { Neglect } \\ (n=50)\end{array} & \chi^{2}\end{array}$

\begin{tabular}{|c|c|c|c|c|}
\hline \multicolumn{5}{|l|}{ Measures in infancy } \\
\hline Fretful baby & $24.5 \%(n=48)$ & $21.1 \%(n=28)$ & $13.3 \%(n=6)$ & 2.75 \\
\hline Feeding problems & $35.4 \%(n=69)$ & $30.2 \%(n=39)$ & $37.8 \%(n=17)$ & 1.27 \\
\hline Delayed walking/talking & $16.7 \%(n=33)$ & $15.2 \%(n=20)$ & $22.2 \%(n=10)$ & 1.21 \\
\hline Unwanted pregnancy & $13.5 \%(n=26)$ & $25.0 \%(n=32)$ & $40.4 \%(n=19)$ & $28.07^{*}$ \\
\hline \multicolumn{5}{|l|}{ Parental background } \\
\hline \multicolumn{5}{|l|}{ Background of adversity } \\
\hline Father & $25.4 \%(n=46)$ & $25.4 \%(n=31)$ & $31.6 \%(n=12)$ & 0.66 \\
\hline Mother & $32.8 \%(n=64)$ & $41.4 \%(n=53)$ & $39.1 \%(n=18)$ & 2.60 \\
\hline \multicolumn{5}{|l|}{ Background of poverty } \\
\hline Father & $30.7 \%(n=55)$ & $32.5 \%(n=39)$ & $27.0 \%(n=10)$ & 0.41 \\
\hline Mother & $19.0 \%(n=37)$ & $16.5 \%(n=21)$ & $10.9 \%(n=5)$ & 1.77 \\
\hline \multicolumn{5}{|l|}{ Background of unhappiness } \\
\hline Father & $26.4 \%(n=47)$ & $33.3 \%(n=39)$ & $27.0 \%(n=10)$ & 1.72 \\
\hline Mother & $35.4 \%(n=69)$ & $34.6 \%(n=44)$ & $36.4 \%(n=16)$ & 0.05 \\
\hline \multicolumn{5}{|l|}{ Lack of higher schooling } \\
\hline Father & $89.3 \%(n=167)$ & $88.5 \%(n=115)$ & $82.2 \%(n=37)$ & 1.76 \\
\hline Mother & $76.4 \%(n=149)$ & $70.0 \%(n=91)$ & $78.7 \%(n=37)$ & 2.20 \\
\hline \multicolumn{5}{|c|}{ Erratic or unsatisfactory job record } \\
\hline Father & $3.6 \%(n=7)$ & $12.6 \%(n=17)$ & $46.9 \%(n=23)$ & $66.90 *$ \\
\hline Mother & $13.5 \%(n=26)$ & $21.9 \%(n=28)$ & $22.2 \%(n=10)$ & 4.47 \\
\hline \multicolumn{5}{|c|}{ History of significant illness/poor health } \\
\hline Father & $25.0 \%(n=47)$ & $27.5 \%(n=36)$ & $56.5 \%(n=26)$ & $18.09 *$ \\
\hline Mother & $26.5 \%(n=52)$ & $32.1 \%(n=43)$ & $40.4 \%(n=19)$ & 3.81 \\
\hline \multicolumn{5}{|l|}{ Parental traits } \\
\hline "Dull" mother & $8.5 \%(n=17)$ & $19.9 \%(n=27)$ & $34.0 \%(n=17)$ & $22.14^{*}$ \\
\hline Father's severe nervousness & $9.0 \%(n=17)$ & $17.6 \%(n=23)$ & $20.8 \%(n=10)$ & 7.30 \\
\hline
\end{tabular}


International Journal of Child, Youth and Family Studies (2011) 1 \& 2: 65-82

\begin{tabular}{|c|c|c|c|c|}
\hline & $\begin{array}{l}\text { No Neglect } \\
(n=202)\end{array}$ & $\begin{array}{l}\text { Possible Neglect } \\
(n=138)\end{array}$ & $\begin{array}{l}\text { Neglect } \\
(n=50)\end{array}$ & $\chi^{2}$ \\
\hline Mother’s severe nervousness & $12.6 \%(n=25)$ & $18.0 \%(n=24)$ & $20.0 \%(n=10)$ & 2.75 \\
\hline Father unhealthy at time of interview & $14.8 \%(n=27)$ & $20.2 \%(n=26)$ & $53.2 \%(n=25)$ & $32.78 *$ \\
\hline Mother unhealthy at time of interview & $19.0 \%(n=38)$ & $30.3 \%(n=40)$ & $49.0 \%(n=24)$ & $19.33^{*}$ \\
\hline \multicolumn{5}{|c|}{ High-risk family environment $(K R-20=0.71)$} \\
\hline Inadequate family income & $8.9 \%(n=18)$ & $28.3 \%(n=39)$ & $62.0 \%(n=31)$ & $68.62^{*}$ \\
\hline Poor housing & $25.7 \%(n=52)$ & $40.6 \%(n=56)$ & $74.0 \%(n=37)$ & $41.02 *$ \\
\hline Family supported by social agencies & $9.4 \%(n=19)$ & $18.1 \%(n=25)$ & $74.0 \%(n=37)$ & $102.54 *$ \\
\hline Convicted older siblings & $4.5 \%(n=9)$ & $14.5 \%(n=20)$ & $30.0 \%(n=15)$ & $28.33^{*}$ \\
\hline Inconsistent parental discipline & $11.3 \%(n=21)$ & $39.4 \%(n=50)$ & $61.7 \%(n=29)$ & $60.67 *$ \\
\hline Slack rules by parents & $6.7 \%(n=13)$ & $14.7 \%(n=20)$ & $73.3 \%(n=33)$ & $113.06 *$ \\
\hline Parents' poor marital relations & $13.3 \%(n=26)$ & $31.1 \%(n=41)$ & $65.3 \%(n=32)$ & $56.88^{*}$ \\
\hline \multicolumn{5}{|l|}{ Parental criminality } \\
\hline Criminal record of parents & $19.8 \%(n=40)$ & $25.4 \%(n=35)$ & $54.0 \%(n=27)$ & $24.34 *$ \\
\hline \multicolumn{5}{|l|}{ Problem behavior $(K R-20=0.66)$} \\
\hline Risk-taking/Adventurousness & $13.2 \%(n=26)$ & $21.1 \%(n=28)$ & $45.7 \%(n=21)$ & $24.76^{*}$ \\
\hline Resistance to discipline & $15.7 \%(n=31)$ & $29.9 \%(n=41)$ & $49.0 \%(n=24)$ & $26.02 *$ \\
\hline Problematic conduct disorder of boy & $5.2 \%(n=10)$ & $24.4 \%(n=31)$ & $41.3 \%(n=19)$ & $43.93 *$ \\
\hline Daring (peer rating) & $25.7 \%(n=46)$ & $26.3 \%(n=31)$ & $38.9 \%(n=14)$ & 2.73 \\
\hline Troublesome (peer rating) & $20.1 \%(n=36)$ & $21.2 \%(n=25)$ & $36.1 \%(n=13)$ & 4.55 \\
\hline \multicolumn{5}{|c|}{ Teacher's rating of school maladjustment $(K R-20=0.73)$} \\
\hline Problem behavior & $5.0 \%(n=10)$ & $23.2 \%(n=32)$ & $34.0 \%(n=17)$ & $37.15^{*}$ \\
\hline Poor work or laziness & $35.2 \%(n=69)$ & $50.4 \%(n=69)$ & $67.3 \%(n=33)$ & $19.09 *$ \\
\hline Lack of interest (doesn’t care) & $9.7 \%(n=19)$ & $30.4 \%(n=41)$ & $54.2 \%(n=26)$ & $50.52 *$ \\
\hline Poor attendance & $19.0 \%(n=37)$ & $23.4 \%(n=32)$ & $40.0 \%(n=20)$ & $9.85 \dagger$ \\
\hline Lack of concentration & $44.2 \%(n=87)$ & $63.5 \%(n=87)$ & $61.2 \%(n=30)$ & $13.57 *$ \\
\hline Difficult relations with peers & $16.4 \%(n=32)$ & $31.3 \%(n=41)$ & $43.5 \%(n=20)$ & $18.82 *$ \\
\hline \multicolumn{5}{|l|}{ Cognitive abilities $(K R-20=0.66)$} \\
\hline Low mechanical reading quotient & $16.8 \%(n=33)$ & $24.3 \%(n=33)$ & $60.0 \%(n=30)$ & $39.79 *$ \\
\hline Poor arithmetic ability (teacher rating) & $30.8 \%(n=60)$ & $39.5 \%(n=51)$ & $55.8 \%(n=24)$ & $10.15 \dagger$ \\
\hline Low verbal IQ & $16.8 \%(n=34)$ & $24.4 \%(n=33)$ & $58.0 \%(n=29)$ & $36.43^{*}$ \\
\hline Low non-verbal IQ & $15.3 \%(n=31)$ & $29.0 \%(n=40)$ & $54.0 \%(n=27)$ & $33.52 *$ \\
\hline
\end{tabular}

$* p<.001 \quad \dagger<.01$

Note: No neglect group $=0$ neglect factor; possible neglect group $=1-3$ neglect factors; neglect group $=4$ or more neglect factors. Due to multiple comparisons, the Bonferroni correction was applied and the alpha-level has been adjusted to $p<.001$ (.05 / 44 comparisons).

Interestingly, measures in infancy are not significantly associated with the extent of exposure to neglect. The only exception relates to the unwanted pregnancy of the mother, which is relatively more common among the neglect group (40.4\%) when compared to the possible neglect (25\%) and no neglect (13.5\%) groups. Further, parental background characteristics also generally fail to distinguish the three groups. A background of adversity, poverty, and unhappiness of parents, as well as their educational attainments, is not significantly associated 
with neglect. However, the father's erratic employment record (46.9\% for the neglect group versus $12.6 \%$ for PN and 3.6\% for NN groups) and history of significant illnesses (56.5\% for neglect group versus $27.5 \%$ for PN and $25 \%$ for NN) are significantly more prevalent among the males in the neglect group when compared to the other groups.

Table 1 also shows that the social worker rating of a "dull” mother (a British term that refers to a slow-witted individual) is more common among the neglect group (34\%, $n=17)$ when compared to the PN $(19.9 \%, n=27)$ and $\mathrm{NN}(8.5 \%, n=17)$ groups. While the severe nervousness of parents is not significantly associated with neglect, individuals in the neglect group were more likely to have parents who were in poor health at the time of the interview; about half of the neglect group had at least one unhealthy parent.

Nearly all indicators of family risk are significantly associated with increased likelihood of neglect. Children in the neglect group are more likely to come from families with inadequate income (62\% versus $28.3 \%$ and $8.9 \%$ for possible neglect and no neglect groups, respectively), poor housing (74\% versus $40.6 \%$ and $25.7 \%$ ), older siblings with convictions (30\% versus $14.5 \%$ and $4.5 \%$ ), inconsistencies in parental discipline (61.7\% versus $39.4 \%$ and $11.3 \%$ ), slack rules (73.3\% versus $14.7 \%$ and $6.7 \%)$, and poor marital relationship (65.3\% versus $31.1 \%$ and $13.3 \%)$. Perhaps most interestingly, there is a significantly higher prevalence of families that are supported by social agencies among the neglect group (74\% versus $18.1 \%$ and $9.4 \%$ of the PN and NN groups). This finding may suggest that families of neglected children have been, at an early stage, formally identified as having special needs. Parental criminality is also significantly more prevalent among the neglect group (54\%) when compared to the PN (25.4\%) and NN (19.8\%) groups.

Most measures of problem behaviors (risk-taking and adventurousness, resistance to discipline, and problematic conduct disorder) are associated with neglect, though the differences across the groups do not appear to be as substantial as for the indicators of high-risk family environment. Risk-taking and adventurousness are more prevalent in the neglect group (45.7\% versus $21.1 \%$ for the PN and $13.2 \%$ for the $\mathrm{NN}$ ), as is resistance to discipline (49\% versus $29.9 \%$ and $15.7 \%$ ) and problematic conduct disorder (41.3\% versus $24.4 \%$ and $5.2 \%$ ). There are no significant differences in peer ratings of daring behaviors and troublesomeness across the three groups.

Measures of school maladjustment, which are based on teacher ratings, also emerge as significant correlates of neglect. Individuals in the neglect group exhibit more problem behavior in school (34\% versus $23.2 \%$ for the PN and 5\% for the NN), show more signs of laziness or poor work (67.3\% versus 50.4\% and 35.2\%), lack interest (52.2\% versus $30.4 \%$ and $9.7 \%$ ) and concentration (61.2\% versus $63.5 \%$ and $44.2 \%$ ), have poor attendance ( $40 \%$ versus $23.4 \%$ and $19 \%)$, and have more difficult relations with their peers (43.5\% versus $31.3 \%$ and $16.4 \%$ ) when compared to the NN and PN groups. Finally, the bottom section of Table 1 shows that neglected children are significantly more likely to have limited cognitive abilities (low mechanical reading quotient, poor arithmetic ability, and low verbal and non-verbal IQ) when compared to the other groups (see Perez \& Widom, 1994).

Overall, Table 1 suggests that neglected children are more likely than other groups to be exposed to other childhood risk factors. As such, it is important to consider all factors 
International Journal of Child, Youth and Family Studies (2011) 1 \& 2: 65-82

simultaneously when assessing the relationship between childhood neglect and later life outcomes. While these analyses do not enable us to draw conclusions about the direction or sequencing of associations, they do illustrate the concurrence between childhood neglect and other risk factors.

Table 2. Mean Differences in Age 8-10 Risk Factor Constructs between the Three Neglect Groups.

$\begin{array}{lllll} & \begin{array}{l}\text { No Neglect } \\ (n=202)\end{array} & \begin{array}{l}\text { Possible Neglect } \\ (n=138)\end{array} & \begin{array}{l}\text { Neglect } \\ (n=50)\end{array} & \chi^{2} \\ \text { Problem behavior } & 0.76(1.11), 0 & 1.23(1.37), 1.0 & 2.13(1.77), 2.0 & 33.62^{* *} \\ \text { Low cognitive abilities } & 0.80(1.08), 0 & 1.21(1.33), 1.0 & 2.32(1.39), 2.5 & 47.67^{* *} \\ \text { Family risk } & 0.82(1.05), 1.0 & 1.87(1.54), 2.0 & 4.40(1.73), 5.0 & 128.9^{* *} \\ \text { School maladjustment } & 1.29(1.47), 1.0 & 2.25(1.76), 2.0 & 2.97(1.89), 3.0 & 45.63^{* *} \\ & & & \\ * * \text { * } p<.001 & & \end{array}$

Table 2 summarizes the information in Table 1, and presents mean and median differences in key childhood risk constructs (problem behavior, cognitive abilities, high-risk family, and school maladjustment) between the neglect groups. Table 2 illustrates a steady progression in risk construct scores with increased exposure to neglect. Internal reliability was low for measures in infancy as well as parental traits and background, and thus it was not possible to create scales with these items. Moreover, these variables were generally not significantly associated with the degree of exposure to neglect.

Table 3 investigates the predictive power of neglect and other childhood risk factors on the prevalence of convictions in adolescence. It has been suggested that some of the risk factors (namely those reflecting problem behaviors) may measure the same underlying construct as offending (e.g., antisocial personality), and that these measures should be excluded from an analysis of offending behavior (see Amdur, 1989). Instead of removing these constructs entirely from the analyses, we have entered them consecutively in separate models in order to better assess the independent effect of neglect on official offending in adolescence. The measures were entered in order of strength of correlation with neglect, from the weakest to the strongest correlates. The variables were entered in four steps: neglect, behavioral outcomes (problem behavior and school maladjustment), cognitive abilities, and family risk measures (parental criminality and high-risk family environment). The risk factors were split at the median and dichotomized, due to the skewed distributions. Two dummy variables were created for the neglect groups, with the no neglect group serving as the reference category. 
International Journal of Child, Youth and Family Studies (2011) 1 \& 2: 65-82

Table 3. Logistic Regression Analysis: Dependent Variable $=$ Juvenile Conviction (0 $=$ no conviction, $1=$ at least one conviction), $n=382$.
B
SE
Wald
$\operatorname{Exp}(B)$

Model 1

Neglect group (no neglect)

Possible neglect

0.31

0.30

1.12

1.37

Neglect

1.47

0.35

17.44

$4.35^{* * *}$

Model $\chi^{2}$

$16.93 * * *$

-2LL

Nagelkerke $\mathrm{R}^{2}$

0.07

\section{Model 2}

Neglect group (no neglect)

Possible neglect

Neglect

School maladjustment

Problem behavior

Model $\chi^{2}$

-2LL

Nagelkerke $\mathrm{R}^{2}$

\section{Model 3}

Neglect group (no neglect)

Possible neglect

Neglect

School maladjustment

Problem behavior

Low cognitive abilities

Model $\chi^{2}$

$44.19 * * *$

$-2 L L$

337.01

Nagelkerke $\mathrm{R}^{2}$

0.17

0.03

0.99

0.62

0.89

$-0.07$

0.70

0.23

0.95

1.10
0.31

0.37

0.29

0.31
0.01

7.05

4.53

8.35
1.03

$2.70^{* * *}$

$1.85^{*}$

$2.44^{* *}$

\section{Model 4}

Neglect group (no neglect)

Possible neglect

Neglect

School maladjustment

Problem behavior

Low cognitive abilities

High-risk family

Parental criminality

Model $\chi^{2}$

-2LL

$62.53^{* * *}$

$-0.27$

0.11

0.32

0.05

0.93

3.29

$2.02 \dagger$

0.55

1.26

9.07

0.31

0.34

10.37

$2.58 * *$

2.99***

$-0.02$

0.95

1.06

0.80

0.87
0.34
0.43

0.33

0.32

0.34

0.33

0.30
0.63

0.06

0.01

8.51

9.39

5.70

8.31

$* p<.05$

$\dagger<.10$
0.76

1.11

0.98

$2.58 * *$

$2.87 * *$

2.23*

$2.40 * *$

$* * * p<.001$

$* * \boldsymbol{p}<.01$

(1)


Model 1 in Table 3 shows significant differences in the odds of juvenile conviction between the no neglect and neglect groups, but not between the no neglect and possible neglect groups. The odds of being convicted in adolescence are 4.35 times higher for individuals in the neglect group when compared to individuals who did not have any exposure to neglect (Wald = 17.44 , odds $=4.35, p<.01$ ). These findings are consistent with those of Widom and Maxfield (2001), who found that abused and neglected children were more likely to be arrested when compared to non-abused and non-neglected individuals. This significant association is maintained when introducing measures of problem behavior (Model 2), but significantly attenuated $(p<.10)$ with the inclusion of the measure of low cognitive abilities (Model 3). Interestingly, school maladjustment is not significantly associated with the odds of conviction in adolescence when taking into account low cognitive abilities. It seems that problem behaviors at school and juvenile convictions do not necessarily reflect the same underlying construct in this sample of British males. In the last model, the introduction of family risk factors renders the differences between the NN and neglect groups non-significant, but the measures of low cognitive abilities, problem behavior, high-risk family environment, and parental criminality remain significantly associated with increased odds of juvenile conviction when all measures are considered simultaneously. Interactions between neglect and all other risk factors were also examined, none of which were significant. It is also interesting to note that similar results were obtained when controlling for self-reported offending, with the exception of a slightly higher explained variance.

Table 4. OLS Regression Analysis: Dependent Variable = Self-Reported Offending Gravity in Adolescence (Logged), $n=375$.

\begin{tabular}{llllllll}
\multicolumn{3}{c}{} & Model 1 & & \multicolumn{3}{c}{ Model 2} \\
$b$ & $S E$ & $\beta$ & $t$ & $b$ & $S E$ & $\beta$ & $t$
\end{tabular}

Neglect group (no neglect)

Possible neglect

Neglect

0.09

0.06

0.08

1.54

$0.03 \quad 0.06$

0.03

0.47

Low cognitive abilities

School maladjustment

Problem behavior

High-risk family

Parental criminality

$0.22 \quad 0.08$

0.14

$2.60 * *$

0.04

0.10

0.03

$0.19 \quad 0.06$

$0.183 .06 * *$

- - - -

$\begin{array}{ll}-0.01 & 0.06\end{array}$

$-0.01-0.06$

- $-4-$

$0.13 \quad 0.06$

$0.12 \quad 2.24 *$

- $\quad-\quad-$

$0.01 \quad 0.06$

0.01

0.18

$0.12 \quad 0.07$

0.10

$1.84 \dagger$

$\mathbf{R}^{2}$

$* * * p<.001$
$* * p<.01$
.01

${ }^{*} \boldsymbol{p}<.05$
.06

$\dagger<.10$

Table 4 presents results relating to the relationship between neglect and other risk factors measured at ages 8 to 10 on self-reported offending in adolescence. Similarly to results observed for official offending, significant differences emerge only between the groups that are at the two extremities of the neglect continuum (no neglect and neglect, see Model 1). Neglected boys are 
characterized by higher self-reported gravity scores in adolescence. However, this association dissipates in Model 2, and low cognitive abilities and problem behavior become the only significant predictors of self-reported offending gravity in adolescence. It is particularly interesting to note that the other childhood risk factors are not predictive of self-reported offending behavior in adolescence, though parental criminality is nearly significant. The interactions between neglect and risk factors were not found to be significant.

Two points are noteworthy. The exclusion of the measure of problem behavior from the analyses does not alter the results: neglect remains a significant predictor of self-reported offending gravity in the first model, and only low cognitive abilities emerge as a significant predictor when the full model is considered. It should also be noted that the analyses presented in Table 4 were replicated with four other measures of self-reported offending: age of onset, frequency, versatility, and seriousness. These comparisons showed similar results, namely the non-significant effect of neglect on self-reported delinquency when other childhood risk factors are taken into account.

\section{Discussion}

The objective of the current study was to identify a group of men in the Cambridge study who were neglected during childhood, to describe their individual, social, and family characteristics when compared to non-neglected men, and to examine whether exposure to childhood neglect predicted offending behavior in adolescence.

Three key findings emerge. First, boys who were neglected in childhood tended to belong to disadvantaged families, exhibit more problem behaviors at home and at school, and have more limited cognitive abilities. In other words, these neglected boys were characterized by a variety of adverse childhood factors placing them at risk for delinquency. Second, our findings indicate that childhood neglect dramatically increased the odds of being convicted of an offense as an adolescent $(\mathrm{OR}=4.35)$ and significantly predicted self-reported offending. However, these effects were attenuated (in the case of official offending) or disappeared entirely (in the case of self-reports) when controlling for other childhood risk factors. Thus, these new findings suggest that these earlier childhood risk factors associated with neglect may provide a link to understanding how childhood neglect, in addition to physical and sexual abuse, leads to increased risk for delinquency. While the assessments in the Cambridge study began at an early age (age 8), earlier assessments may shed some light on whether the development of behavior problems occurs a result of exposure to neglect earlier in childhood. On the other hand, the explained variance in analyses predicting offending was relatively low (particularly for selfreported offending), suggesting that other important predictors of juvenile delinquency may have been omitted for this sample of British males. Third, our findings indicate that neglect and other childhood risk factors were better predictors of official crime than self-reports of offending in adolescence, possibly indicating the negative effects of the stigma attributed to children identified as neglected or from problem families.

Despite the importance of early detection and intervention in cases of child abuse and neglect, our findings suggest some unintended consequences of the early identification of such cases. The fact that neglect and other risk factors measured in childhood are better predictors of 
officially recorded crime when compared to self-report may suggest the presence of stigmatization effects. As Widom (2003) noted earlier, although it is important to identify abused and neglected children early and to detect signs of trouble, it is also critical to be sensitive to the potential negative effects of increased attention and surveillance. This attention may represent a "double-edged sword”, in which children become labeled and stigmatized, or expectations of delinquency and crime for these children are prophesied. Care must be taken to prevent this early identification from becoming a self-fulfilling prophecy.

\section{Future Research}

While the purpose of the current paper was to identify a group of boys from the Cambridge Study who were victims of childhood neglect and to examine the impact of neglect on offending in adolescence, further analyses are needed to investigate the mediating processes between childhood neglect and offending behavior that are suggested by the present results. Future studies will attempt to unravel the explanatory mechanisms that may link childhood neglect to offending behavior and other life outcomes. This study has also not examined the impact of the neighborhood context as a potential moderating factor in the association between child neglect and criminal behavior, and recent research suggests that it may be worthwhile to examine this contribution (e.g., see Schuck \& Widom, 2005). These analyses have focused on externalizing behaviors. However, some have suggested that childhood neglect may be associated with internalizing and withdrawn behaviors (Arata et al., 2005; Hildyard \& Wolfe, 2002; Manly et al., 2001). Thus, it may be worthwhile to examine the impact of childhood neglect on internalizing (depression, anxiety, etc.) and other externalizing behaviors (substance use, offending, sexual promiscuity, etc.) of the boys in the Cambridge Study. The data used in this study did not include specific information about parental experiences of abuse and neglect, and few indicators of parental traits were collected in childhood. More comprehensive measures of these constructs are needed to examine the potential intergenerational transmission of maltreatment behaviors. Finally, it would have been interesting to contrast the impact of neglect in childhood and in adolescence in order to test Thornberry, Ireland, and Smith's (2001) assertion that adolescent (or persistent) maltreatment exerts a more pronounced effect on adverse outcomes (delinquency, substance use, depression, etc.) when compared to maltreatment that is limited to childhood. However, the Cambridge Study does not include indicators of neglect in adolescence.

In conclusion, the current study has identified a group of boys in the Cambridge Study of Delinquent Development who were neglected in childhood. The CSDD offers rich, longitudinal data that enables the study of the long-term effects of childhood neglect, a topic that remains understudied and misunderstood (National Research Council, 1993). Additional research is needed to better understand the mechanisms that link childhood neglect to later offending and other life outcomes. 
International Journal of Child, Youth and Family Studies (2011) 1 \& 2: 65-82

\section{References}

Allen, B. (2008). An analysis of the impact of diverse forms of childhood psychological maltreatment on emotional adjustment in early adulthood. Child Maltreatment, 13(3), 307-312.

Amdur, R. L. (1989). Testing causal models of delinquency: A methodological critique. Criminal Justice and Behavior, 16(1), 35-62.

Arata, C. M., Langhinrichsen-Rohling, J., Bowers, D., \& O’Farrill-Swails, L. (2005). Single versus multi-type maltreatment: An examination of the long-term effects of child abuse. Journal of Aggression, Maltreatment \& Trauma, 11(4), 29-52.

Bolger, K. E., \& Patterson, C. J. (2001). Pathways from child maltreatment to internalizing problems: Perceptions of control as mediators and moderators. Development and Psychopathology, 13(4), 913-940.

Chapple, C. L., Tyler, K. A., \& Bersani, B. E. (2005). Child neglect and adolescent violence: Examining the effects of self-control and peer rejection. Violence and Victims, 20(1), 3953.

Cohen, P., Smailes, E., \& Brown, J. (2004). Effects of childhood maltreatment on adult arrests in a general population sample (No. NCJ 199707). Washington, DC: National Institute of Justice.

Colman, R. A., \& Widom, C. S. (2004). Childhood abuse and neglect and adult intimate relationships: A prospective study. Child Abuse \& Neglect, 28(11), 1133-1151.

Dutton, D. G., \& Hart, S. D. (1992). Evidence for long-term, specific effects of childhood abuse and neglect on criminal behavior in men. International Journal of Offender Therapy and Comparative Criminology, 36(2), 129-137.

English, D. J., Widom, C. S., \& Brandford, C. (2002). Childhood victimization and delinquency, adult criminality, and violent criminal behavior: A replication and extension. Final Report presented to the National Institute of Justice (No. Grant No. 97-IJ-CX-0017). Washington, DC: U.S. Department of Justice, National Institute of Justice.

Fagan, A. (2001). The gender cycle of violence: Comparing the effects of child abuse and neglect on criminal offending for males and females. Violence and Victims, 16(4), 457474.

Farrington, D. P. (2003). Key Results from the first forty years of the Cambridge Study in Delinquent Development. In T. P. Thornberry \& M. D. Krohn (Eds.), Taking stock of delinquency: An overview of findings from contemporary longitudinal studies (pp. 137183). New York: Kluwer Academic/Plenum Publishers. 
International Journal of Child, Youth and Family Studies (2011) 1 \& 2: 65-82

Farrington, D. P., Coid, J. W., Jolliffe, D., Soteriou, N., Turner, R., \& West, D. J. (2006). Criminal careers up to age 50 and life success up to age 48: New findings from the Cambridge Study in Delinquent Development (Home Office Research Study No. 299). London: Home Office.

Farrington, D. P., Coid, J. W., \& West, D. J. (2009). The development of offending from age 8 to age 50: Recent results from the Cambridge Study in Delinquent Development. Monatsschrift fur Kriminologie und Strafrechtsreform, 92, 160-173.

Glaser, D. (2002). Emotional abuse and neglect (psychological maltreatment): A conceptual framework. Child Abuse \& Neglect, 26(6-7), 697-714.

Hildyard, K. L., \& Wolfe, D. A. (2002). Child neglect: developmental issues and outcomes. Child Abuse \& Neglect, 26(6-7), 679-695.

Horwitz, A. V., Widom, C. S., McLaughlin, J., \& White, H. R. (2001). The impact of childhood abuse and neglect on adult mental health: A prospective study. Journal of Health and Social Behavior, 42(2), 184-201.

Jones, L. M., Finkelhor, D., \& Halter, S. (2006). Child maltreatment trends in the 1990s: Why does neglect differ from sexual and physical abuse? Child Maltreatment, 11(2), 107-120.

Kazemian, L., \& Farrington, D. P. (2005). Comparing the validity of prospective, retrospective, and official onset for different offending categories. Journal of Quantitative Criminology, 21(2), 127-147.

Kazemian, L., Farrington, D. P., \& Le Blanc, M. (2009). Can we make accurate long-term predictions about patterns of de-escalation in offending behavior? Journal of Youth and Adolescence, 38(3), 384-400.

Lansford, J. E., Miller-Johnson, S., Berlin, L. J., Dodge, K. A., Bates, J. E., \& Pettit, G. S. (2007). Early physical abuse and later violent delinquency: A prospective longitudinal study. Child Maltreatment, 12(3), 233-245.

Le Blanc, M., \& Fréchette, M. (1989). Male criminal activity from childhood through youth: Multilevel and developmental perspectives. New York: Springer-Verlag.

Legano, L., McHugh, M. T., \& Palusci, V. J. (2009). Child abuse and neglect. Current Problems in Pediatric and Adolescent Health Care, 39, 31.e31-31.e26.

Manly, J. T., Kim, J. E., Rogosch, F. A., \& Cicchetti, D. (2001). Dimensions of child maltreatment and children's adjustment: Contributions of developmental timing and subtype. Development and Psychopathology, 13(4), 759-782.

Mersky, J. P., \& Reynolds, A. J. (2007). Child maltreatment and violent delinquency: Disentangling main effects and subgroup effects. Child Maltreatment, 12(3), 246-258. 
International Journal of Child, Youth and Family Studies (2011) 1 \& 2: 65-82

National Research Council. (1993). Understanding child abuse and neglect. Washington, DC: National Academy Press.

Nikulina, V., Widom, C. S., \& Czaja, S. J. (in press). The role of childhood neglect and childhood poverty in predicting mental health, academic achievement and crime in adulthood. American Journal of Community Psychology.

Perez, C. M., \& Widom, C. S. (1994). Childhood victimization and long-term intellectual and academic outcomes. Child Abuse \& Neglect, 18(8), 617-633.

Rodgers, C. S., Lang, A. J., Laffaye, C., Satz, L. E., Dresselhaus, T. R., \& Stein, M. B. (2004). The impact of individual forms of childhood maltreatment on health behavior. Child Abuse \& Neglect, 28(5), 575-586.

Schuck, A. M., \& Widom, C. S. (2005). Understanding the role of neighborhood context in the long-term criminal consequences of child maltreatment. American Journal of Community Psychology, 36(3/4), 207-222.

Smith, C. A., Ireland, T. O., \& Thornberry, T. P. (2005). Adolescent maltreatment and its impact on young adult antisocial behavior. Child Abuse \& Neglect, 29(10), 1099-1119.

Smith, C. A., \& Thornberry, T. P. (1995). The relationship between childhood maltreatment and adolescent involvement in delinquency. Criminology, 33(4), 451-481.

Stouthamer-Loeber, M., Loeber, R., Homish, D. L., \& Wei, E. (2001). Maltreatment of boys and the development of disruptive and delinquent behavior. Development and Psychopathology, 13(4), 941-955.

Thornberry, T. P., Ireland, T. O., \& Smith, C. (2001). The importance of timing: The varying impact of childhood and adolescent maltreatment on multiple problem outcomes. Development and Psychopathology, 13(4), 957-979.

Tyler, K. A., Johnson, K. A., \& Brownridge, D. A. (2008). A longitudinal study of the effects of child maltreatment on later outcomes among high-risk adolescents. Journal of Youth and Adolescence, 37(5), 506-521.

U.S. Department of Health and Human Services. (2010a). Child Maltreatment 2008. Washington, D.C.: Administration for Children and Families, Administration on Children, Youth and Families, Children's Bureau.

U.S. Department of Health and Human Services. (2010b). Definitions of Child Abuse and Neglect: Summary of State Laws. Retrieved December 2, 2010, from http://www.childwelfare.gov/systemwide/laws_policies/statutes/define.cfm

West, D. J., \& Farrington, D. P. (1973). Who Becomes Delinquent? London: Heinemann.

Widom, C. S. (1989). Child abuse, neglect, and violent criminal behavior. Criminology, 27(2), 251-271. 
International Journal of Child, Youth and Family Studies (2011) 1 \& 2: 65-82

Widom, C. S. (2003). Understanding child maltreatment and juvenile delinquency: The research. In J. K. Wiig, C. S. Widom, \& J. A. Tuell (Eds.), Understanding child maltreatment \& juvenile delinquency: From research to effective program, practice, and systemic solutions (pp. 1-10). Washington, DC: CWLA Press.

Widom, C. S., Czaja, S. J., \& Dutton, M. A. (2008). Childhood victimization and lifetime revictimization. Child Abuse \& Neglect, 32(8), 785-796.

Widom, C. S., DuMont, K. A., \& Czaja, S. J. (2007). A prospective investigation of major depressive disorder and comorbidity in abused and neglected children grown up. Archives of General Psychiatry, 64(1), 49-56.

Widom, C. S., \& Maxfield, M. G. (2001). An update on the "cycle of violence". Washington, D.C.: U.S. Department of Justice, Office of Justice Programs, National Institute of Justice.

Widom, C. S., Raphael, K. G., \& DuMont, K. A. (2004). The case for prospective longitudinal studies in child maltreatment research: Commentary on Dube, Williamson, Thompson, Felitti, and Anda (2004). Child Abuse \& Neglect, 28(7), 715-722.

Widom, C. S., White, H. R., Czaja, S. J., \& Marmorstein, N. R. (2007). Long-term effects of child abuse and neglect on alcohol use and excessive drinking in middle adulthood. Journal of Studies on Alcohol and Drugs, 68(3), 317-326.

Williams, L. M., \& Herrera, V. M. (2007). Child maltreatment and adolescent violence: Understanding complex connections. Child Maltreatment, 12(3), 203-207.

Wolfgang, M. E., Figlio, R. M., Tracy, P. E., \& Singer, S. I. (1985). The National survey of crime severity. Washington, DC: U.S. Department of Justice, Bureau of Statistics.

Zingraff, M. T., Leiter, J., Myers, K. A., \& Johnsen, M. C. (1993). Child maltreatment and youthful problem behavior. Criminology, 31(2), 173-202.

Zuravin, S. J. (1999). Child neglect: A review of definitions and measurement research. In H. Dubowitz (Ed.), Neglected children: Research, practice and policy (pp. 24-46). Thousand Oaks, CA: Sage. 